\title{
Pacific Overtures
}

\author{
Text by Clark L. Beck and Ardath W. Burksı
}

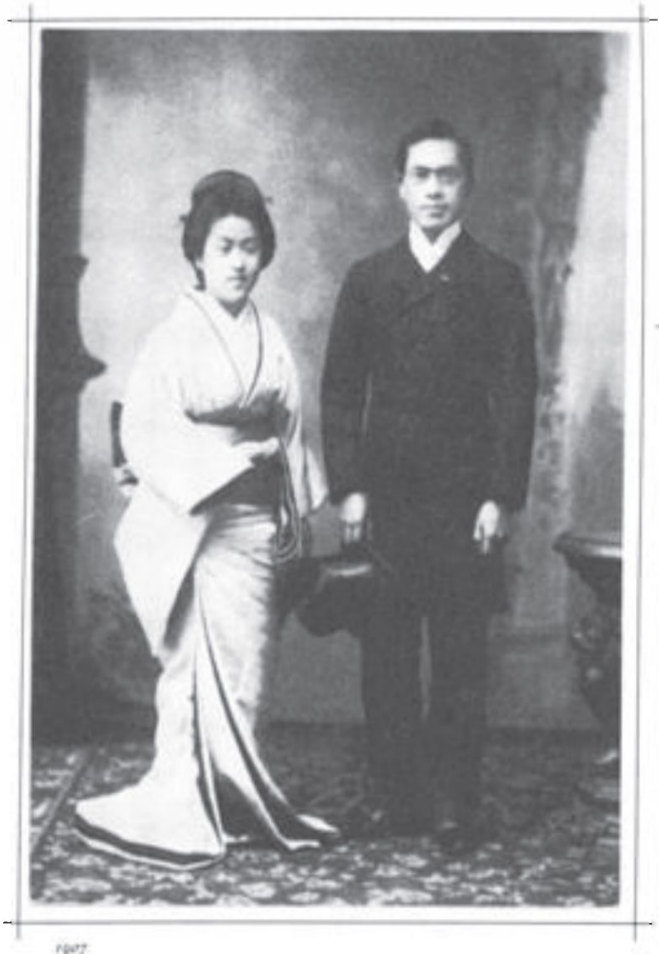

nopt

For many Americans, the first image of Japan has been linked to the name and exploits of Commodore Matthew Perry. Even at the time Perry "opened" Japan, there was in America intense interest in the island nation, an interest heightened by the U.S. government's publication of detailed accounts of the expedition (1853-54). The original flag journals kept for the commodore clearly demonstrate that the visitors

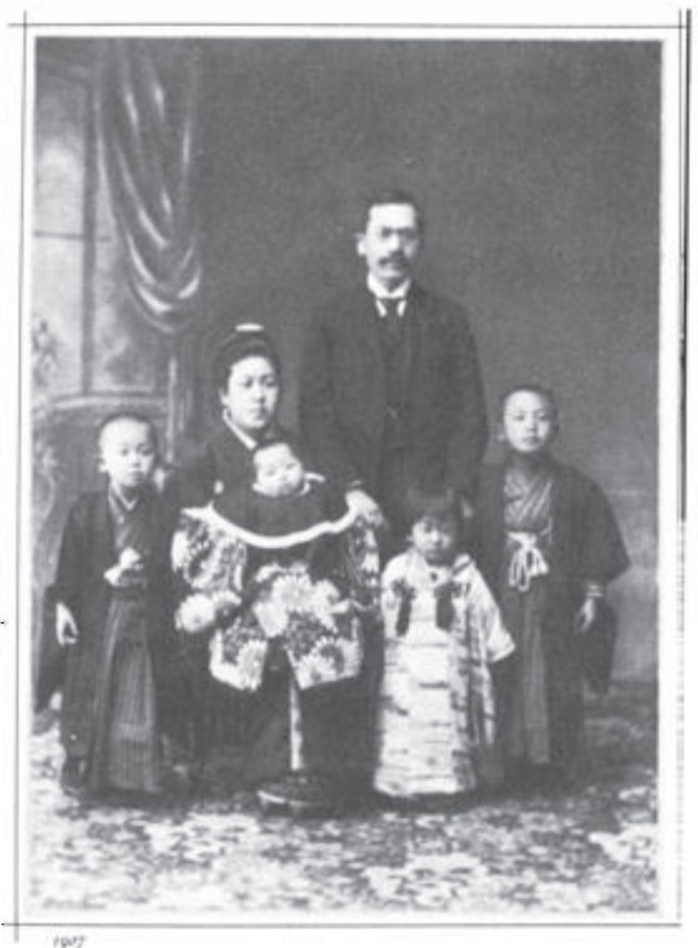
were as impressed by what they saw as were the Japanese by the long-nosed foreigners.

"This photographic essay first appeared in Social Science and Modern Society I 9 (July/ August 1982). Reprinted with permission." 
Since the Perry expedition, images of Japanometimes highly conflicting - have been piled atop nages. Few have been as historically important as the rst impressions gathered in the nineteenth century.

For many Japanese (and in the view of contempoary Western scholars of Japan), the Perry expedition ras a catalyst, precipitating important change in their ountry. The commodore's arrival was the occasion for, ot the basic cause of, the fateful transition. In the Dinion of many Japanese, the critical period came uring the twilight of the hegemony established twond-a-half centuries earlier by the Tokugawa family. It ras the end of one regime (what the Japanese call the zkumatou) and the beginning of another. The climax ame, something over a century ago, with the so-called ieiji Restoration (1868), which paved the way for the codernization of Japan.
In the first few years after 1868 , the entire political, economic, and social structure was redesigned. In 1871 , the last vestiges of formal feudalism were surgically removed. By 1873 , the reformers, the Meiji modernizers, had moved into positions of leadership. By 1875 , they had arrested Western expansion and guaranteed Japan's subsequent escape from the unequal treaty status suffered by the Chinese for decades thereafter. By the 188 os and 1890 s, the Meiji leadership had adapted foreign imports to the Japanese model, successfully combining traditional Japanese values with modern Western technology.

In Japan's transition from an isolated, feudal society to a modern state, resident foreigners played a critical role, one often misunderstood. With these alien advisers, technical assistants, and teachers, the Japanese engaged in one of the most interesting experiments in

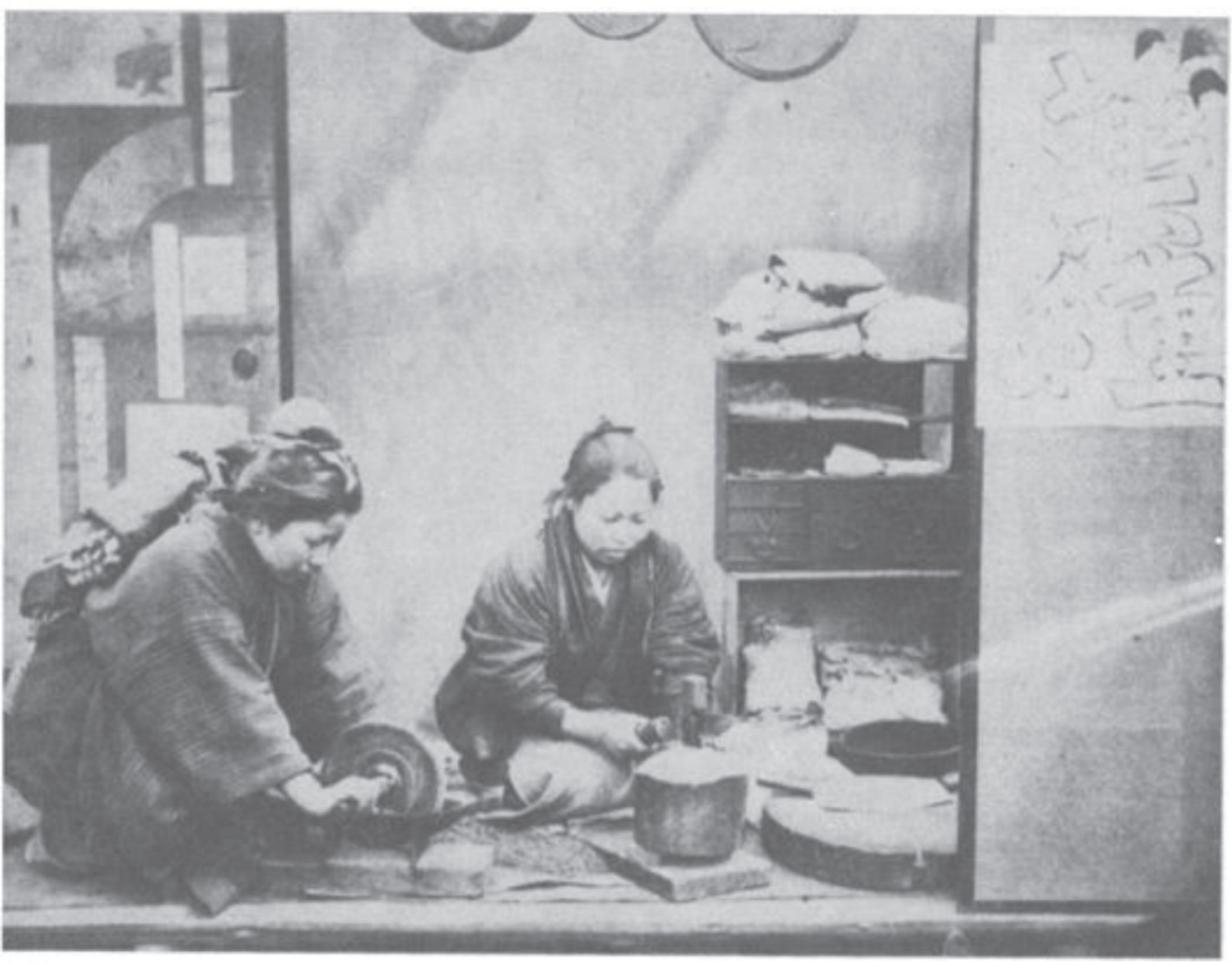




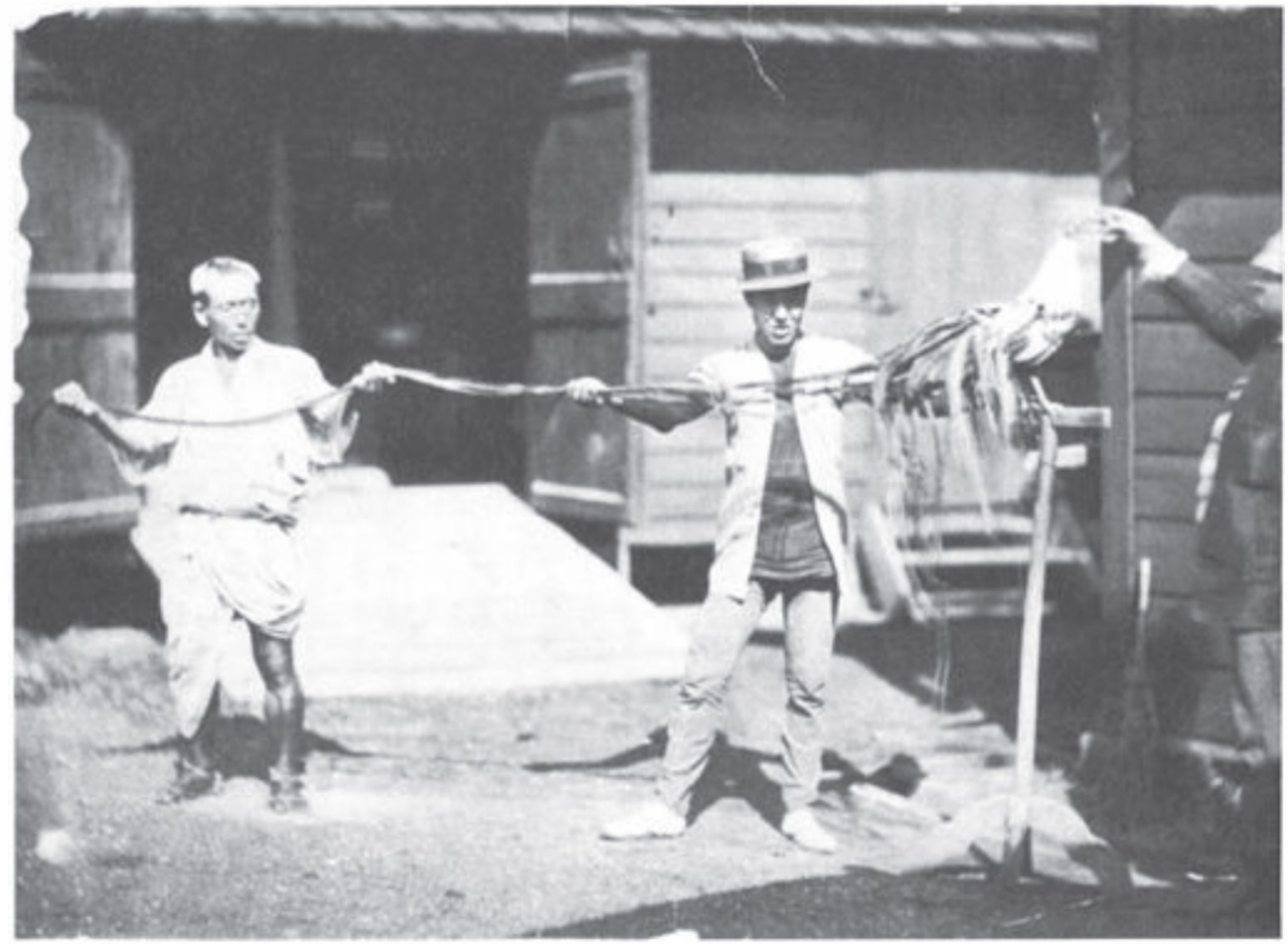

massive borrowing from abroad the world has ever seen. It has been estimated that official, governmentsponsored foreign employees (the oyatoi gaikokujin) lent the Meiii government some 9.500 man-years of counsel and aid. Nonetheless, from the beginning (as some of the foreign advisers like William Elliot Griffis, Guido Verbeck, David Murray, and Ernest Fenellosa realized) the Japanese set the goals of modernization, paid for and managed the technical assistance, and implemented the policies of directed change. The remark able "ministers of modernization" (the men of Meiji) were usually in complete control of the process. The oyatoi played significant but marginal roles. Despite some appearances, Japan was not "Westernized"; it was, for better or worse, "modernized."

These photographs are drawn largely from the Griffis Collection in the Alexander Library, Rutgers University. They formed part of a special exhibit, "As We Saw Them: Westerners Interpret Japan, 1853-1912," prepared and catalogued by Clark L. Beck and Ardath W. Burks. 


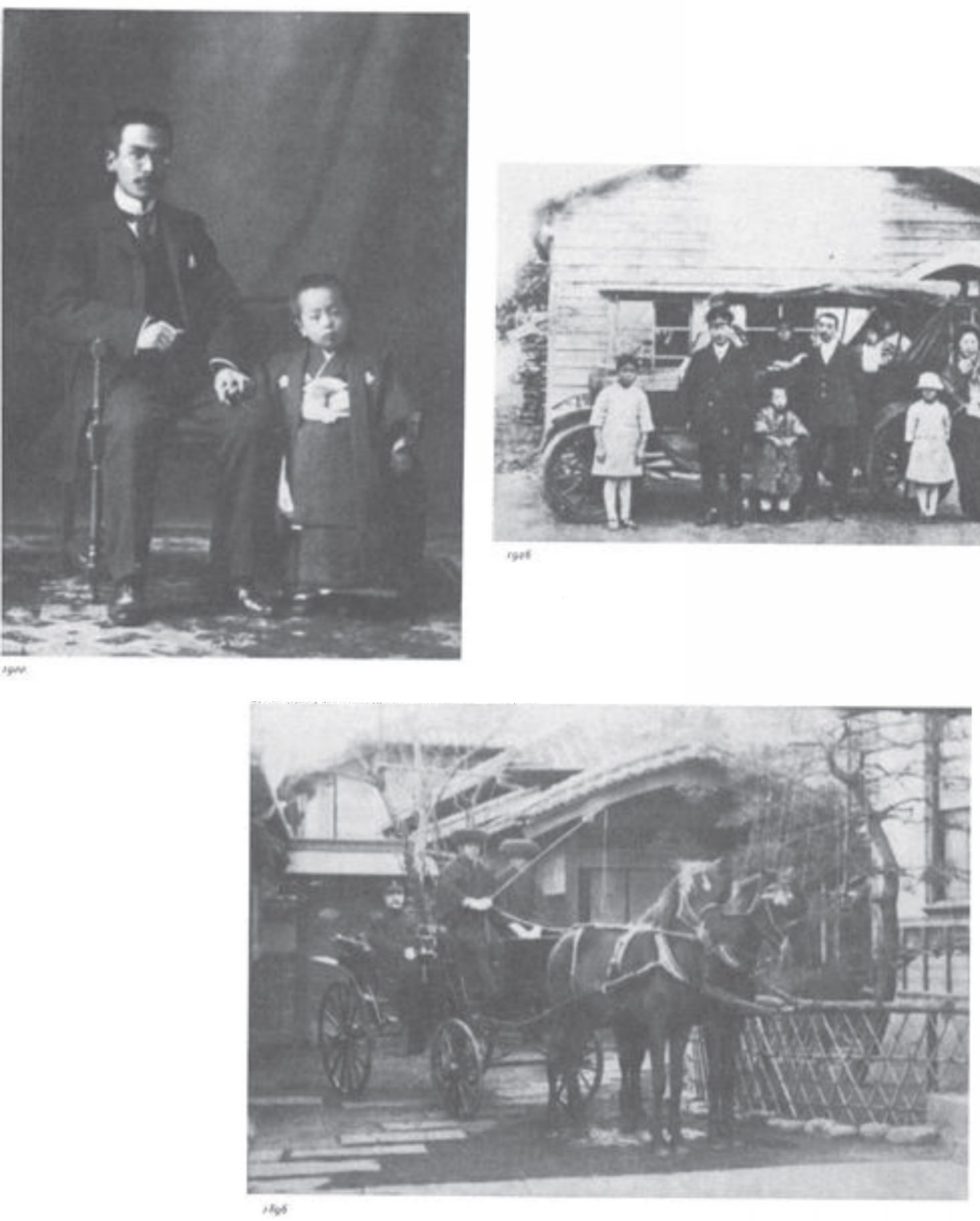




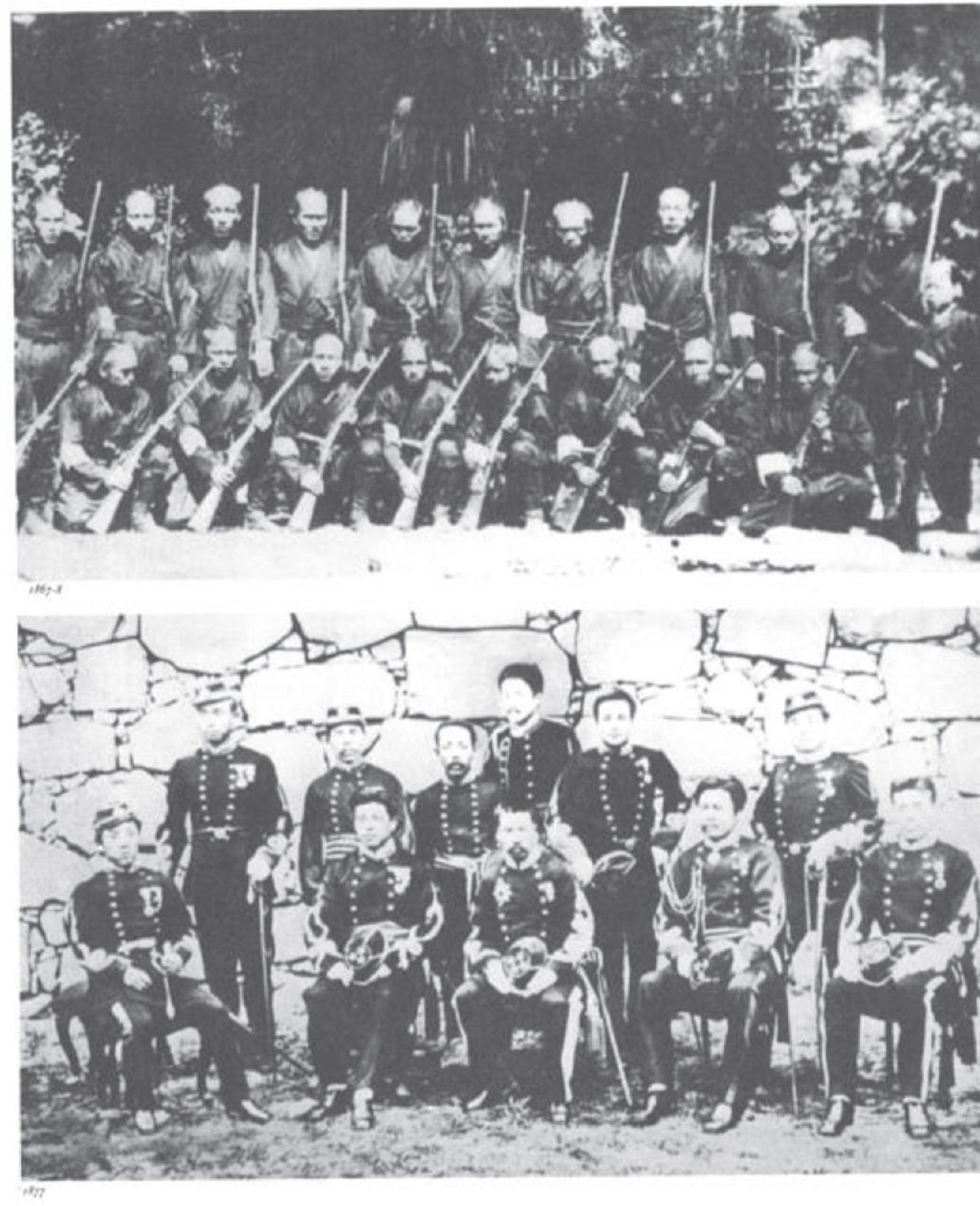

